\title{
Economic Sizing of a Hybrid (PV-WT-FC) Renewable Energy System (HRES) for Stand-Alone Usages by an Optimization- Simulation Model: Case study of Iran
}

\author{
R. Hosseinalizadeh ${ }^{\mathrm{a}}, \ldots$... Shakouri G. ${ }^{\mathrm{a}, \mathrm{b}}, \ldots$ \\ a. School of Industrial and Systems Engineering, College of Engineering, University of Tehran, Iran \\ b. Institute for Resource, Environment and Sustainability, University of British Columbia, Canada
}

\begin{abstract}
Hybrid renewable energy systems, combining various kinds of technologies, have shown relatively high capabilities to solve reliability problems and have reduced cost challenges. The use of hybrid electricity generation/storage technologies as off-grid stand-alone systems is reasonable to overcome related shortcomings. Solar and wind energy are two rapidly emerging renewable ones that have precedence in comparison to the other kinds. In this regard, the present paper studies four specific locations in Iran, which are candidates for research centers. Based on the solar radiation and average wind speed maps, techno-economically optimized systems are designed by simulating behavior of various combinations of renewable energy systems with different sizing, including wind turbine (WT), photovoltaic (PV), Fuel cell (FC), and battery banks. According to the results obtained by a computer program, it is concluded that the hybrid systems including WT and PV with battery backup are less costly compared to the other systems. Moreover, we found that among non-hybrid systems, in most regions of Iran's territory PVs are more economical than WTs. Despite of its advantages, FC has not been applied in the optimal systems due to its high initial cost and its low replacement life.
\end{abstract}

Keyword: Hybrid renewable energy systems, techno-economic analysis, WT, PV, Fuel Cell

Nomenclature 


\begin{tabular}{|c|c|c|c|}
\hline$P_{P V}:$ & PV system output power & $\beta$ & PV cell Temperature coefficient of efficiency \\
\hline$I_{T}:$ & Solar radiation & $T_{c}$ & Average PV cell temperature \\
\hline$\eta:$ & PV system efficiency & $B V$ & Battery Voltage \\
\hline$A_{P V}:$ & The area of PV panel & $P E$ & The primary stored energy in battery \\
\hline$\eta_{p c:}$ & PV Auxiliary equipment Efficiency & $T_{a}$ & Ambient temperature \\
\hline$\eta_{e c:}$ & PV module efficiency & NOCT & Normal operation cell temperature \\
\hline$\eta_{r}$ & Rated PV module efficiency & $T_{a, N O C T}$ & Ambient temperature of $N O C T$ \\
\hline$T_{r}$ & The temperature of Rated efficiency & $I_{N O C T}$ & Solar radiation in $N O C T$ \\
\hline$T_{c}$ & PV Cell temperature & $A$ & WT Swept Area \\
\hline$C_{p, t h}$ & The Power coefficient of WT & $H w_{1}$ & The height of measured wind velocity \\
\hline$\rho$ & Air density & $V_{2}$ & Wind velocity in $\mathrm{Hth}_{2}$ \\
\hline$H t h_{2}$ & The height of WT hub & $V_{1}$ & Wind velocity in $H w_{l}$ \\
\hline$\alpha$ & Hellman coefficient & $B C$ & Battery bank capacity \\
\hline$B D O D$ & Battery bank Depth Of Discharge & $B V$ & Battery bank Voltage \\
\hline$L O L$ & Loss of load & $L O L E$ & Loss of load expectation \\
\hline$L O E$ & Loss Of Energy & $L O E E$ & Loss of energy expectation \\
\hline$C R F$ & Capital recovery factor & $O M$ & Operation and maintenance cost \\
\hline$U S F W$ & Uniform Series of a Future Worth & $S V$ & Scrap value \\
\hline$C O E$ & Cost Of Energy & RES & Renewable energy system \\
\hline HRES & Hybrid Renewable energy system & $S P S$ & Standalone power system \\
\hline $\mathrm{H}_{2}$ & Hydrogen & $S E S B$ & Surplus energy stored in the battery \\
\hline$S E B$ & Stored energy in the battery & SEHP & Surplus energy used for hydrogen producing \\
\hline$S E$ & Surplus energy & $B R E$ & Battery bank recharge efficiency \\
\hline
\end{tabular}

\section{Introduction}

In the recent years, due to the value of non-energy uses of fossil fuel products in industry (e.g. petrochemical industries that produce various valuable products by reforming methane and propane), along with high prices of crude oil and global environmental problems, new energy resources have been extremely emerging all around the world. Fossil energy resources are exhaustible, while the prices are influenced by various political factors, as well as economic conditions. On the other hand, compared to conventional technologies, economy of renewable energy technologies plus reliability issues of the resources are yet obstacles, which slow down fast replacement of clean abundant new energies for their old competitors. However, the use of hybrid renewable energy systems as stand-alone systems for remote areas, like environmental research centers, could be a reasonable approach to overcome the mentioned weaknesses [1]. Hence, using these technologies could turn out to be affordable in remote areas as a stand-alone hybrid system due to the high costs for network extension [2]. 
In single renewable systems, such as WT and PV, derived energy is unreliable due to instability. The purpose of combining renewable energy technologies is to exploit the strengths of one technology that covers the weaknesses of others so that the reliability of the entire system is increased and economic and environmental aspects are improved [3, 4].

One of the major challenges, encountered when using stand-alone RESs, is their need for energy storage systems because of the unpredictable nature of their resources. Energy storage plays an important role in the development and operation of a renewable system in a Stand-alone Power Systems (SPS). Several energy storage techniques, such as batteries, flywheels, and hydrogen production for use in FC are available. In a SPS, the main parameters to optimize the energy storage systems are their capacity, resource availability, and the response time of the storage system. Traditionally, batteries are used for energy storage; despite maturity of their technology and market, costs and disposal (or salvage) after their lifetime are batteries limitations. In addition, batteries need maintenance; their performance depends on the working temperature that should be controlled during the operation time. What is more, batteries' self-discharging is a bottleneck, especially in cold regions. However, normal batteries offer good modularity, fasttime response, and good energy-mass ratio storage.

In comparison to the batteries, FCs also present good modularity and the possibility of partial working, as well as good energy storage capability, that can be simply attained by correct sizing of a Hydrogen Tank (HT). The main weakness of FCs is its slow dynamics [3]; they have high time constants, which mean much time they need to start the production process. Furthermore, the maintenance of FCs is still a problem because of catalyst replacement issues. Alternatively, a battery bank becomes a good choice for short-term energy storage owing to its high chargingdischarging efficiency along with its capability to counteract and take care of the equipment in face of the effects of instantaneous demands and wind energy's fluctuation. On the other hand, because of their low energy density and self-discharging, batteries are not appropriate for longterm storage. Conversely, $\mathrm{H}_{2}$ as the fuel of FCs is well suited for storage applications in longer periods for its high energy density. Therefore, a combination of battery banks with long-term energy storage in the form of $\mathrm{H}_{2}$ can significantly improve the performance of stand-alone $\mathrm{RE}$ systems, where the electrolyzer (EL) generates $\mathrm{H}_{2}$ while excess solar and wind energy is available as well. When solar and wind energy is not sufficient, the FC employs this $\mathrm{H}_{2}$ to 
produce electricity. Table 1 summarizes the main cons and pros for these systems individually which can be compensated with the other in a hybrid system.

Table 1

Cons and pros of battery and FC

There are many issues to be studied in case of hybrid systems. Shakya et al. [5] 0in 2005 studied the combination of modified diesel engine with hydrogen fuel, WT, and PV to supply the demand of an educational and interpretive center in Australia. In 2009 Saheb et al. [6] published a paper in which they had described the techno-economic aspect of the combination of WT and PV with diesel backup systems, simulating its behavior for residential demand in remote areas. Furthermore Dursun [7] in 2012 studied techno-economic aspect of PV and FC for a campus in Turkey. In 2012 Genc et al. [8] carried out a study on Hybrid systems in Turkey. In this study the energy demand of a chicken farm in Pinarbasi was supplied by using a Wind-FC-EL energy system. Also Abedi et al. [9] in 2011 researched on the techno-economic aspects of a hybrid system that contains WT, PV, and FC for a region in the North West of Iran. Moreover, in their 2012 study, Abdolrahimi et al. [10] simulated and compared two hybrid systems in Iran, the former containing WT and PV and the latter containing WT and PV with diesel backup system. In 2012 and 2013 Asrari and Ghasemi [11, 12] studied the different combination of WT, PV, Battery, and Diesel Generator for a remote village in Iran, and Fallahi et al. [13] optimized a hybrid PV/Wind/Tidal system for a port in south of Iran. Also, Ren et al. [14] have evaluated hybrid energy storage technologies for a solar-wind generation system.

Among the conducted studies, various tools and methods are used to achieve the goals. For instance, Amutha et al. [15], Velo [16] and [17-19] have used HOMER, whereas [5, 20] have employed TRNSYS. THERMIE [21] and WindHyGen [22, 23] are also other software used by others. Moreover, [24-26] have made a use of Simulink, while LABVIEW has been used to model a hybrid energy system by Eroglua [27]. A review of software tools for hybrid energy systems has been presented in [28]. From another point of view, researchers have taken a variety of approaches to search for the best solutions. This variety shapes a spectrum of methods from simple to difficult. As an example, Genc [8] has adopted mathematical programming, while a simple economic analysis is applied by Malik [29]. On the other side, artificial intelligence has 
been used by researchers such as HongXing [30]. A review of different approaches for optimum design of hybrid renewable energy systems has been presented in [31].

In addition to classification by tools, some researchers have classified the literature by other aspects. For instance, Bajpai [3] has divided sizing methods into two groups, based on the availability of weather-related factors such as irradiance, clearness index, and wind speed. As a second example, Luna [32] has focused on complexity level of sizing methods, reaching to four groups: Probabilistic, Analytical, Iterative, and Hybrid. The summary of other works in the literatures are presented in Table 2 in order to facilitate comparison to the present study.

Another issue is dispatch strategy of hybrid energy systems. There are different strategies to backup systems control. In a hybrid system consisting of battery without any backup system, the dispatch strategy is simple: when there is excessive power from the base system, the battery is recharged and when there is a lack of power, it is supplied by the battery. Conversely, if a hybrid system consists of a backup system, the dispatch strategy can be complicated, wherein the procedure of supplying loads with less priority in energy shortage time must be specified, as well as the charging procedure of the batteries.

The two most widely used strategies in literature are Load Following Strategy (LFS) and Cycle Following Strategy (SFS). In the former the backup system produces energy only as much as the amount of production which satisfies the main demand. In this regard, supplying less priority loads, such as battery charging demand, is the base subsystem task. In the latter strategy, however, once the backup system starts, it works in full capacity to supply main demand; then its surplus power is allocated to satisfy less priority loads like battery charging. The operation of backup systems in the best efficiency is the advantage of this strategy.

In various studies, the results are different in accordance with climatic conditions, data and parameters. Saheb [6], Shakya [5], and Asrari [11] and Ngan [19] have concluded that the hybrid systems are not optimal. Saheb considers a solar/wind/diesel hybrid system in six various Algerian's climatic zones and the obtained economic results show that PV systems represent more competitive solution than hybrid systems in all the sites. Shakya has carried out the technical feasibility and financial analysis of a stand-alone wind-PV hybrid system incorporating a hydrogen storage subsystem (compressed gas storage) for Cooma-Australia revealed that the PV system has the lowest levelized energy cost among configurations considered in this study. 
Furthermore, Asrari has studied different combinations of grid, solar, wind and diesel systems in Binalood region that has one of the best wind potentials in Iran. In his study, grid has been extended to the region and so renewable systems are not economical but results suggest that wind turbines can still offer some help with $32 \%$ reduction in emissions of $\mathrm{CO}_{2}$ by a $44 \%$ rise in net present costs (NPC). Ngan has studied different hybrid systems including wind, PV, diesel system and battery bank and has compared them with stand-alone diesel system. His results show that hybrid systems are not the most economical but they reduce the dependence on diesel resource. Although, the Cost of Energy $(C O E)$ of these systems are higher than that of diesel only system, they can significantly reduce the fuel consumptions. In addition, these systems help to reduce the emission of $\mathrm{CO}_{2}$ gas of approximately $30 \%$ and $34.5 \%$ respectively. In this study, wind-grid system is the most affordable one among the hybrid systems. On the other hand, the use of FC have not been identified as an economical choice by Leva [33] and Karakoulidis [34], while another research, published by Kashefi [35], has identified that a hybrid systems including FC can be an optimal system.

Table 2

Literature review

\begin{tabular}{|c|c|c|c|c|c|c|c|c|c|}
\hline Author's & Year & WT & PV & FC & Bat & Diesel & Other & Method & Tools \\
\hline Khan et al. [36] & 2009 & 1 & - & $\mathscr{l}$ & - & - & - & Simulation & Simulink \\
\hline Leva et al. [33] & 2009 & & 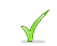 & $\mathscr{L}$ & $\mathscr{L}$ & $\mathscr{A}$ & - & $?$ & THERMIE $^{1}$ \\
\hline Karakoulidis et al. [34] & 2011 & - & 1 & $\mathscr{L}$ & $\mathbb{1}$ & $\mathscr{l}$ & - & $?$ & HOMER \\
\hline Abedi et al. [9] & 2011 & $\vartheta$ & $\mathbb{P}$ & $\mathscr{1}$ & - & - & - & $\begin{array}{l}\text { Mixed Integer Nonlinear } \\
\text { Optimization Problem }\end{array}$ & $?$ \\
\hline Jallouli et al. [37] & 2012 & - & $\mathbb{1}$ & $\mathscr{l}$ & $\mathscr{l}$ & - & - & $?$ & Simulink \\
\hline Abdolrahimi et al. [38] & 2012 & & & - & $d$ & $\mathscr{L}$ & - & $?$ & HOMER \\
\hline Asrari et al. [11] & 2012 & 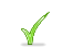 & $\mathscr{L}$ & - & $\mathscr{l}$ & $\mathscr{L}$ & - & $?$ & HOMER \\
\hline Fallahi et al. [13] & 2012 & $\alpha$ & $x$ & - & & - & $\begin{array}{l}\text { Tidal power } \\
\text { plant }\end{array}$ & $\begin{array}{l}\text { Optimization - Exact } \\
\text { methods }\end{array}$ & LINGO \\
\hline Amer et al. [39] & 2013 & 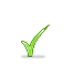 & 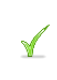 & - & $\mathscr{L}$ & $\mathscr{L}$ & - & $\begin{array}{l}\text { Particle Swarm Optimization } \\
\text { Technique }\end{array}$ & $?$ \\
\hline Iverson et al. [40] & 2013 & & & $\mathscr{L}$ & - & - & - & $\begin{array}{l}\text { Optimization routine } \\
\text { employing a search algorithm }\end{array}$ & $?$ \\
\hline Ghasemi et al. [12] & 2013 & - & $I$ & - & $\mathscr{L}$ & $\mathscr{L}$ & - & - & HOMER \\
\hline Feroldi et al. [41] & 2014 & $\sqrt{ }$ & $\mathbb{Y}$ & $\mathscr{1}$ & y & - & $\begin{array}{l}\text { Bioethanol } \\
\text { Reformer }\end{array}$ & Genetic algorithm & $?$ \\
\hline Tao Ma et al. [42] & 2014 & $\mathscr{L}$ & 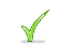 & - & $\mathscr{L}$ & - & - & $?$ & HOMER \\
\hline Rohani et al. [43] & 2014 & $\mathscr{l}$ & $\mathscr{1}$ & - & $\mathscr{L}$ & $\mathscr{L}$ & - & $?$ & HOMER \\
\hline Nogueira et al. [44] & 2014 & $\mathscr{L}$ & $\mathbb{I}$ & - & $\mathscr{1}$ & - & - & $\begin{array}{l}\text { Iterative procedure in } \\
\text { Linear Programming }\end{array}$ & MATLAB \\
\hline
\end{tabular}

\footnotetext{
${ }^{1}$ Programme (EEC) for the promotion of energy technology in Europe
} 
In the present article, due to high costs of the backup systems like FCs, a battery bank is the storage system and a Proton Exchange Membrane Fuel Cells (PEMFC) plays role of the backup system for the battery bank. In this method, the battery bank supplies the energy shortage, just like the other methods. The backup system, i.e. PEMFC, instead of supplying the load, recharges the battery bank whenever the charge level drops under the allowed amount.

Based on the solar radiation potential map of Iran (Fig 1), four regions, Moaleman, Ghadamgah, Marvdasht, and Nikouyeh have been selected and the appropriate composition has been obtained according to the results of system simulation-optimization.

Fig 1: The solar radiation potential map of Iran

The average wind speed and solar radiation in these regions are presented in Table 3, along with the average temperature, which is required for calculating the efficiency of PV systems. Although a negative correlation has been found between wind speed and solar radiation in some regions [13], it is not the case for all regions. If an optimal allocation problem was encountered, such a correlation would be important, but herein specific locations are aimed to be supplied by renewable energies. The objective of this study is to study techno-economical feasibility of a stand-alone hybrid PV-WT-FC system for a research center in the four regions in Iran with a steady demand of $10 \mathrm{~kW}$.

Table 3

Climate data of four studied regions

\section{System Simulation}

A hybrid system, composed by several components, where each can take various sizes, there are many possible combinations. For optimizing characteristics of such a hybrid renewable energy system, first we have to generate different systems with different sizes of components. Then, their dynamic behaviors should be simulated. Finally, regarding the average energy costs, among from the investigated hybrid systems, the most economical one is selected. In order to render the 
obtained results applicable, the restrictions and the requirements of both supply and demand sides must be satisfied at every moment (calculated hourly in this study) and the relationships between the components of system must be taken into consideration. To assure technical feasibility of the systems, it is required to simulate their hourly operation in various conditions. This is done by developing a computer program.

\subsection{Energy, Produced from RESs}

The proposed system consists of WT, PV, FC, Battery, EL, and HT, with unknown capacities. The capacities of the EL and HT are proportional to the capacity of FC, meaning that both have zero capacities if the capacity of FC is zero. The structure of this system is presented in Fig 2.

Fig 2: General schematic of the designed system

\subsubsection{Modeling and Simulating a PV system}

The output power of a Multi-Crystalline PV system with an area of $A_{p v}$ facing solar radiation is calculated by the following formula $[1,45]$ :

$$
P_{P V}=I_{T} \times \eta \times A
$$

where $I_{T}$ is the total radiation onto one square meter in one hour, and $\eta$ is the overall efficiency obtained by:

$$
\eta=\eta_{e c} \times \eta_{p c}
$$

with $\eta_{p c}$ representing the efficiency of the auxiliary equipment of the system, and $\eta_{e c}$ denoting the module efficiency. The impact of temperature variations on the module efficiency is theoretically calculated by the following equation $[1,5,45,46]$ :

$$
\eta_{e c}=\eta_{r}\left[1-\beta\left(T_{c}-T_{r}\right)\right]
$$

where $T_{c}$ is computed based on the instantaneous ambient temperature, $T_{a}$, by:

$$
T_{c}=T_{a}+\left(\frac{N O C T-T_{a, N O C T}}{I_{N O C T}}\right) \times I_{T}
$$

Both the definitions and values of the parameters are given in Table 4 [1, 5, 45, 46].

Table 4

Used data for simulation of Crystalline PVs 


\subsubsection{Modeling and Simulation of a WT}

The energy output generated by a WT with $A \mathrm{~m}^{2}$ swept area is measured by means of the following equation $[30,47]$ :

$$
P\left(V_{2}\right)=\frac{1}{2} \times C_{P, t h} \times \rho \times A \times V_{2}^{3}
$$

where $C_{p, t h}$ is the power coefficient of WT and $V_{2}$ is the wind velocity in the height of turbine hub, $H t h_{2}$, which is calculated by $[45,48]$ according to:

$$
\frac{V_{2}}{V_{1}}=\left(\frac{H t h_{2}}{H w_{1}}\right)^{\alpha}
$$

having $V_{1}$ as the wind velocity in the height of a reference height denoted by $H w_{1}$.

5 presents the corresponding parameters used in this study.

Table 5

WT data

\subsection{Battery Capacity}

The battery capacity is calculated based on the primary stored energy by means of the following equation:

$$
B C=\frac{P E}{B V \times B D O D}
$$

where $P E$ in kWh is the primary needed energy at the beginning of systems life, $B V$ is battery's voltage and $B D O D$ denotes battery's depth of discharge. It represents the percentage of minimum battery capacity that it can be discharged. It should be noted that the efficiency of batteries is related to the batteries recharge and discharge processes, hence calculating their efficiency separately is very difficult. Therefore, producers usually announce an overall efficiency for their batteries. In the present study, just like what Yang H. et al. have done [18], the battery recharging efficiency $(B R E)$ is its nominal efficiency, while the efficiency of battery discharging is assumed to be $100 \%$. The recharge and discharge processes in this study have 
been presented in Fig 4: Simulation flowchartFig 4. In the battery recharge process, if there is surplus energy $(S E)$ to recharge the battery bank and the battery bank has sufficient capacity, $S E$ is used for recharging the battery bank. Otherwise, if there is not sufficient capacity, the battery bank is fully recharged and extra $S E$ is used to produce hydrogen. The energy needed for recharging the battery bank is calculated by the following simple equation:

$$
S E S B=S E \times B R E
$$

where $S E S B$ is the surplus energy stored in the battery. The specifications for a typical battery are presented in Table 6:

Table 6

Battery data

In the battery discharge process, whenever state of charge (SOC) of battery is decreased lower than $25 \%$, fuel cell (FC) is turned on and charges the battery; and whenever SOC is greater than $75 \%$ the FC is turned off.

\subsection{Fuel Cell (FC)}

In the studied system, whenever stored energy in the battery bank falls under the permissible level, the FC is turned on to recharge the batteries. According to PEMFC applications, this kind of FC has been used as the backup system. Furthermore, whenever battery bank lacks sufficient capacity, the battery bank is fully recharged and the extra $S E$ is used to produce hydrogen. The FC Life is regarded hourly $[4,49,50]$. The maximum life of the FC for the backup systems is considered 2000 hours or 500 turn on and off cycles. The cost of FC and its accessories are presented in the following Table 7.

Table 7

The specifications of FC and its accessories

\section{System Optimization}

In this section, the optimization of RES components is explained through introducing the balancing constraints and the objective function. For this purpose, a reliability index should be defined and surveyed during the simulation. Calculation of the system reliability can be done 
using different indexes [6, 9, 35]. In the present study the loss of energy expectation index, $L O E E$, and the loss of load expectation index, $L O L E$, are used. The former index calculates the cost of energy shortage while the latter is used to identify and select the acceptable combinations. These indexes are defined as follows:

$$
\begin{aligned}
L O E E & =\frac{\sum_{t} L O E_{t}}{\sum_{t} E_{t}} \\
L O L E & =\frac{\sum_{t} L O L_{t}}{8760}
\end{aligned}
$$

where, $L O E_{t}$ is the amount of loss of energy, $E_{t}$ is the demand for energy at the $t^{\text {th }}$ time step, and $L O L_{t}$ is the amount of loss of load.

\subsection{The Constraints and the Objective Function}

The constraints and the objective (cost) function of our problem are given below.

\subsubsection{The Constraints}

In this study, several constraints have been used in different part of study. The one of the most important constraint in this study is equality of energy supply side and energy demand side at every moment (Eq. ((11)9)). The Energy supply side contains produced energy by renewable systems and batteries and energy demand side contains energy demand in research centers, the surplus energy stored in the battery bank and the surplus energy used for hydrogen producing $(S E H P)$.

$$
P_{P V}+P_{W T}+P_{B a t}+L O E=\text { Energy Demand }+S E S B+S E H P
$$

Another constraint in this study is about stored energy in the battery bank; energy balance in the battery bank must be considered. This constraint has been presented by following equation:

$$
S E B_{t}=S E B_{t-1}+S E S B_{t}+H B_{t} \times \eta_{F C}-P_{B a t}
$$

where $S E B_{t}$ is the stored energy in the battery at time $t$ and $H B_{t}$ is the used hydrogen for battery charging at time $t$ and $\eta_{F C}$ is the efficiency of FC;

Furthermore, Hydrogen balance in the hydrogen tank must be considered; following expression has been used for this purpose: 


$$
S E H T_{t}=S E H T_{t-1}+S E H B_{t} \times \eta_{E L}-H B_{t}
$$

where SEHT is the stored energy in the hydrogen tank at time $t$ and $\eta_{E L}$ is the efficiency of EL;

And the last constraint is reliability of systems. For this purpose LOLE must be less than $2 \%$.

$$
L O L E \leq 2 \%
$$

\subsubsection{The Objective Function}

To minimize the total energy costs, the optimization algorithm searches the possible solution spaces, specified by the constraints, and selects the combination with the lowest cost. The objective function consists of investment costs, O\&M costs, all replacement costs and unmet demand costs excluding scrap salvage value. Other used data is presented in the Table 8.

The annual real interest rate has an important role affecting the results, which is related to the nominal interest rate by [7]:

$$
i=\frac{i_{0}-f}{1-f}
$$

where $i$ is the real interest rate, $i_{0}$ is the nominal interest rate (the rate at which could the banking system offers a loan), and $f$ is the annual inflation rate.

In Iran, the annual $i_{0}$ is about $25 \%$ and $f$ is around $21 \%$; leading to a real interest rate of $5.06 \%$. Although the $\mathrm{LIBOR}^{2}$ has dramatically dropped in the recent decade, regarding the concurrent economical conditions of the country, we have assumed it to equal $5 \%$.

Table 8

Used data in objective function

Considering the provided information, the objective function is:

$$
\text { Min } C O E=\frac{(C R F \times \text { System initial investment })+O \& M \text { Cost }-(U S F W \times S V)+(\text { Cost of LOE } \times \text { Sum }(L O E))}{365 \times 24 \times \text { Demand Load }-\operatorname{Sum}(L O E))}
$$

where $C R F$ is the Capital Recovery Factor and $U S F W$ is the "Uniform Series of a Future Worth" factor.

\footnotetext{
${ }^{2}$ London Interbank Offered Rate
} 
Fig 3 shows the flowchart of our iterative algorithm that searches the possible solution space for an optimal solution. The simulation of a sample system behavior is presented in Fig 4.

Fig 3: Optimization flowchart

Fig 4: Simulation flowchart

\section{Results}

The simulation results are given for three modes, a hybrid system, a system without WT (PV system), and a system without PV (WT system). The results indicate that in all regions the hybrid mode is the optimum system; nonetheless, the results of the other modes for comparison are included as well. Fig 5 gives the results of optimization for the four mentioned regions, showing $C O E$ and the cost breakdown of the optimum hybrid systems.

Fig 5: The results of optimization $(\$ / \mathrm{KWh})$

As can be seen, in all regions the hybrid mode has the minimum electricity cost. Among the regions, Moaleman has a suitable wind speed $(6.1 \mathrm{~m} / \mathrm{s})$ and high solar potential (5.77 $\mathrm{kWh} / \mathrm{m}^{2}$.day). Therefore, it has the minimum $C O E$ equal to $0.54 \$ / \mathrm{kWh}$, and after this region, Nikouyeh $(0.56 \$ / \mathrm{kWh})$, Marvdasht $(0.62 \$ / \mathrm{kWh})$ and Ghadamgah $(0.799 \$ / \mathrm{kWh})$ have the next best COEs. Solar potential in Nikouyeh is lower than Moaleman but it has better average wind speed, so that its $C O E$ is close to that of Moaleman. Absence of desirable wind in Marvdasht and Ghadamgah has caused their $C O E$ become higher; however, Marvdasht has better solar potential than Ghadamgah.

In all regions except Nikouyeh, after the hybrid mode, PVs have the less $C O E$, rather than WTs. Among the PV systems designed for the regions, Nikouyeh $(C O E=0.63 \$ / \mathrm{kWh})$ and Moaleman $(0.64 \$ / \mathrm{kWh})$ have the minimum $C O E$. Moreover, in WT systems Nikouyeh has the best $C O E$ equal to $0.62 \$ / \mathrm{kWh}$;

The specifications of these hybrid systems depend on the climate conditions. Among these hybrid systems, PV takes the largest share in COE; therefore, decrease in costs of PV causes more reduction in $C O E$, as the initial cost has dropped to less than $2 \$ / \mathrm{W}$ in China and Germany. 
It should be noted that, in a hybrid mode, the capacity of battery bank has been reduced, leading to a decrease in O\&M costs as well as a decrease in the environmental emissions.

Among all, WT systems need the largest battery capacity that is due to irregular nature of wind velocity. Such large battery capacity in WT along with high potential of solar radiation and low potential of wind, has revealed the fact that PVs have less COE compared to that of WTs in the studied regions; e.g. $C O E$ of $\mathrm{PV}$ system in Moaleman is $0.64 \$ / \mathrm{kWh}$ while for WT systems it is $0.92 \$ / \mathrm{kWh}$. The only counterexample is Nikouyeh that has a very good wind potential with 7.2 $\mathrm{m} / \mathrm{s}$ average wind speed. In this region $C O E$ of WT systems is $0.62 \$ / \mathrm{kWh}$ while that of $\mathrm{PV}$ systems is $0.81 \$ / \mathrm{kWh}$. Besides, the results indicate that FCs in spite of their advantages have not been applied in any optimal system owing to their high costs and short lifetime. Hence in offgrid applications, surplus produced energy wastes after that the battery is fully charged.

Fig 6 : The simulation results of hybrid system for four days

The ranks obtained for the regions in different modes are different; for instant, Nikouyeh's hybrid system is the second $(0.56 \$ / \mathrm{kWh})$ and its WT system is the first $(0.62 \$ / \mathrm{kWh})$ and its PV system has the third rank $(0.81 \$ / \mathrm{kWh})$. Similarly, among PV and WT systems, Moaleman has the second rank $(0.64 \$ / \mathrm{kWh}$ and $0.92 \$ / \mathrm{kWh}$, respectively), but in the hybrid mode, its rank is the first $(0.54 \$ / \mathrm{kWh})$. It can be concluded that because of the negative correlations [13], in spite of its ranks in WT and PV modes, these systems supplement each other as hybrid systems and so reduce $C O E$.

Additionally, Fig 6 presents behavior of the optimum hybrid system for four sample days in Marvdasht. In all the four pictures, during the daytime, WT and PV systems meet the energy demand and charge the battery bank. During the nighttime, WT system and battery bank help system to provide the energy demand.

Fig 7: The simulation of WT and PV in Marvdasht

Fig 14 shows the hourly energy generation of PV and WT systems as components of the optimal hybrid system in Marvdasht for five sample days during summer. As expected, generated power by PV system is more regular than generated power by WT system. On the other hand, energy 
generation in WT system is continues at daytime and nighttime but PV system only generates at daytime. Then, use of these systems together can help to reduce $C O E$ and increase the reliability.

In general, it can be concluded that in many areas the hybrid systems are more economical than the single ones. However, regarding the studied regions and according to the weather condition in most parts of Iran, among the non-hybrid systems PV systems are more economical than WT systems with off-grid applications. Additionally, since there is high solar radiation in Iran, PV systems are applicable in most regions, having WT systems a good option for covering the weaknesses of PV systems in the absence of solar radiation. What is more, in areas potentially appropriate for the use of WTs, PVs can be employed to compensate the problems arising from the fluctuating nature of the wind. Table 9 summarizes optimization results for different modes in the studied regions.

Table 9

Optimization results

\section{Conclusion}

The present research studied optimization of hybrid renewable energy systems (HRES), where WT and PV functioned as generation systems, battery banks for storage, and FC is used as a backup system to recharge the batteries. A computer program was used to simulate dynamic behavior of these components. By this program, the different combinations of these components were taken into consideration, so that the system with the minimum costs and the acceptable reliability would be selected as the best combination for HRES. The simulation and optimization were carried out for Moaleman, Marvdasht, Nikouyeh and Ghadamgah, and it was shown that among different systems, the hybrid ones are more economical for an off-grid usage, and among the regions Moaleman has the best $C O E$ equal to $0.54 \$ / \mathrm{kWh}$ and Nikouyeh, Marvdasht and Ghadamgah are the next regions. According to the results, hybrid systems are made of combinations of WT and PV systems in which the batteries are employed to store surplus energy mostly for nighttime. In the best economical systems, the advantages of FC could not cover its high initial costs and its low replacement life, and so was not applied.

In the non-hybrid systems, especially in WT systems, the capacity of battery bank heavily increases and O\&M costs of battery banks in remote area will be a serious problem. Among the 
non-hybrid systems, due to the appropriate potential and relatively regular nature of the solar radiation, less capacity is required for both PV modules and battery banks, compared to wind turbines. As a result, PV systems are more economical than WT systems in the most regions of Iran. Nevertheless, the WTs can be used as a complementary systems, covering the weaknesses of PV systems, reducing costs of the produced energy.

\section{Reference}

[1] Deshmukh MK, Deshmukh SS. Modeling of hybrid renewable energy systems. Renewable and Sustainable Energy Reviews. 2008;12:235-49.

[2] Bernal-Agustín JL, Dufo-López R. Simulation and optimization of stand-alone hybrid renewable energy systems. Renewable and Sustainable Energy Reviews. 2009;13:2111-8. [3] Bajpai P, Dash V. Hybrid renewable energy systems for power generation in stand-alone applications: A review. Renewable and Sustainable Energy Reviews. 2012;16:2926-39.

[4] Zoulias El, Lymberopoulos N. Techno-economic analysis of the integration of hydrogen energy technologies in renewable energy-based stand-alone power systems. Renewable Energy. 2007;32:680-96.

[5] b.d.shakya, aye I, p.musgrave. Technical feasibility and financial analysis of hybrid windphotovoltaic system with hydrogen storage for cooma. international journal of hydrogen energy, elsevier. 2005.

[6] D.Saheb-Koussa, M.Haddadi, M.Belhamel. Economic and technical study of a hybrid system (wind-photovoltaic-diesel) for rural electrification in Algeria. Applied Energy,Elsevier. 2009;86. [7] Dursun B. Determination of the optimum hybrid renewable power generating systems for Kavakli campus of Kirklareli University, Turkey. Renewable and Sustainable Energy Reviews. 2012;16:6183-90.

[8] Genç G, Çelik M, Serdar Genç M. Cost analysis of wind-electrolyzer-fuel cell system for energy demand in Pınarbaşı-Kayseri. International Journal of Hydrogen Energy. 2012;37:1215866.

[9] Abedi S, Ahangar HG, Nick M, Hosseinian SH. Economic and reliable design of a hybrid PVwind-fuel cell energy system using differential evolutionary algorithm. Electrical Engineering (ICEE), 2011 19th Iranian Conference on2011. p. 1-6.

[10] Hatam A, Hossein K. Optimization and sensetivity analysis of a hybrid system for a reliable load supply in kish. INternational journal of advanced renewable energy research. 2012;1:3341.

[11] Asrari A, Ghasemi A, Javidi MH. Economic evaluation of hybrid renewable energy systems for rural electrification in Iran-A case study. Renewable and Sustainable Energy Reviews. 2012;16:3123-30.

[12] Ghasemi A, Asrari A, Zarif M, Abdelwahed S. Techno-economic analysis of stand-alone hybrid photovoltaic-diesel-battery systems for rural electrification in eastern part of Iran-A step toward sustainable rural development. Renewable and Sustainable Energy Reviews. 2013;28:456-62. 
[13] Fallahi N, Nourbakhsh Sh, Shakouri H, Farahani IV. Optimization of a PV/Wind/Tidal Model for Housing Electrification Case Study: Mahshahr, Iran. 11th International Conference on Sustainable Energy Technologies. Vancouver, Canada2012.

[14] Ren L, Tang Y, Shi J, Dou J, Zhou S, Jin T. Techno-economic evaluation of hybrid energy storage technologies for a solar-wind generation system. Physica C: Superconductivity. 2013;484:272-5.

[15] Margaret Amutha W, Rajini V. Techno-economic evaluation of various hybrid power systems for rural telecom. Renewable and Sustainable Energy Reviews. 2015;43:553-61. [16] Velo R, Osorio L, Fernández MD, Rodríguez MR. An economic analysis of a stand-alone and grid-connected cattle farm. Renewable and Sustainable Energy Reviews. 2014;39:883-90.

[17] Abdilahi AM, Mohd Yatim AH, Mustafa MW, Khalaf OT, Shumran AF, Mohamed Nor F. Feasibility study of renewable energy-based microgrid system in Somaliland's urban centers. Renewable and Sustainable Energy Reviews. 2014;40:1048-59.

[18] Shaahid SM, Al-Hadhrami LM, Rahman MK. Economic feasibility of development of wind power plants in coastal locations of Saudi Arabia - A review. Renewable and Sustainable Energy Reviews. 2013;19:589-97.

[19] Ngan MS, Tan CW. Assessment of economic viability for PV/wind/diesel hybrid energy system in southern Peninsular Malaysia. Renewable and Sustainable Energy Reviews. 2012;16:634-47.

[20] Sigarchian SG, Malmquist A, Fransson T. Modeling and Control Strategy of a Hybrid PV/Wind/Engine/Battery System to Provide Electricity and Drinkable Water for Remote Applications. Energy Procedia. 2014;57:1401-10.

[21] Chenni R, Makhlouf M, Kerbache T, Bouzid A. A detailed modeling method for photovoltaic cells. Energy. 2007;32:1724-30.

[22] Diaf S, Diaf D, Belhamel M, Haddadi M, Louche A. A methodology for optimal sizing of autonomous hybrid PV/wind system. Energy Policy. 2007;35:5708-18.

[23] Aguado M, Ayerbe E, Azcárate C, Blanco R, Garde R, Mallor F, et al. Economical assessment of a wind-hydrogen energy system using WindHyGen ${ }^{\circledR}$ software. International Journal of Hydrogen Energy. 2009;34:2845-54.

[24] Sarrias-Mena R, Fernández-Ramírez LM, García-Vázquez CA, Jurado F. Improving grid integration of wind turbines by using secondary batteries. Renewable and Sustainable Energy Reviews. 2014;34:194-207.

[25] Hatti M, Meharrar A, Tioursi M. Power management strategy in the alternative energy photovoltaic/PEM Fuel Cell hybrid system. Renewable and Sustainable Energy Reviews. 2011;15:5104-10.

[26] Koussa DS, Koussa M. A feasibility and cost benefit prospection of grid connected hybrid power system (wind-photovoltaic) - Case study: An Algerian coastal site. Renewable and Sustainable Energy Reviews. 2015;50:628-42.

[27] Eroglua M, Dursun E, Sevencan S, Song J, Yazici S. A mobile renewable house using $\mathrm{PV} /$ wind/fuel cell hybrid power system. international journal of hydrogen energy,elsevier. 2011;36.

[28] Sinha S, Chandel SS. Review of software tools for hybrid renewable energy systems. Renewable and Sustainable Energy Reviews. 2014;32:192-205. 
[29] A.Malik, A.H.Al-Badi. Economics of wind turbine as an energy fuel saver- a case study for remote application in oman. Energy,ELSEVIER. 2009;34:1573-8.

[30] Yang H, Wei Z, Chengzhi L. Optimal design and techno-economic analysis of a hybrid solarwind power generation system. Applied Energy. 2009;86:163-9.

[31] Erdinc O, Uzunoglu M. Optimum design of hybrid renewable energy systems: Overview of different approaches. Renewable and Sustainable Energy Reviews. 2012;16:1412-25.

[32] Luna-Rubio R, Trejo-Perea M, Vargas-Vázquez D, Ríos-Moreno GJ. Optimal sizing of renewable hybrids energy systems: A review of methodologies. Solar Energy. 2012;86:1077-88. [33] Leva S, Zaninelli D. Hybrid renewable energy-fuel cell system: Design and performance evaluation. Electric Power Systems Research. 2009;79:316-24.

[34] Karakoulidis K, Mavridis K, Bandekas DV, Adoniadis P, Potolias C, Vordos N. Technoeconomic analysis of a stand-alone hybrid photovoltaic-diesel-battery-fuel cell power system. Renewable Energy,Elsevier. 2011;36.

[35] Kashefi Kaviani A, Riahy GH, Kouhsari SM. Optimal design of a reliable hydrogen-based stand-alone wind/PV generating system, considering component outages. Renewable Energy. 2009;34:2380-90.

[36] Khan MJ, Iqbal MT. Analysis of a small wind-hydrogen stand-alone hybrid energy system. Applied Energy. 2009;86:2429-42.

[37] Jallouli R, Krichen L. Sizing, techno-economic and generation management analysis of a stand alone photovoltaic power unit including storage devices. Energy. 2012;40:196-209. [38] Abdolrahimi H, Kazemi Karegar H. Optimization and Sensitivity Analysis of a Hybrid System for a Reliable Load Supply in KISH_IRAN. nternational Journal of Advanced Renewable Energy Research (IJARER). 2012; Vol 1, No 4.

[39] Amer M, Namaane A, M'Sirdi NK. Optimization of Hybrid Renewable Energy Systems (HRES) Using PSO for Cost Reduction. Energy Procedia. 2013;42:318-27.

[40] Iverson Z, Achuthan A, Marzocca P, Aidun D. Optimal design of hybrid renewable energy systems (HRES) using hydrogen storage technology for data center applications. Renewable Energy. 2013;52:79-87.

[41] Feroldi D, Zumoffen D. Sizing methodology for hybrid systems based on multiple renewable power sources integrated to the energy management strategy. International Journal of Hydrogen Energy. 2014;39:8609-20.

[42] Ma T, Yang H, Lu L. A feasibility study of a stand-alone hybrid solar-wind-battery system for a remote island. Applied Energy. 2014;121:149-58.

[43] Rohani G, Nour M. Techno-economical analysis of stand-alone hybrid renewable power system for Ras Musherib in United Arab Emirates. Energy. 2014;64:828-41.

[44] Nogueira CEC, Vidotto ML, Niedzialkoski RK, de Souza SNM, Chaves LI, Edwiges T, et al. Sizing and simulation of a photovoltaic-wind energy system using batteries, applied for a small rural property located in the south of Brazil. Renewable and Sustainable Energy Reviews. 2014;29:151-7.

[45] Belmili H, Haddadi M, Bacha S, Almi MF, Bendib B. Sizing stand-alone photovoltaic-wind hybrid system: Techno-economic analysis and optimization. Renewable and Sustainable Energy Reviews. 2014;30:821-32.

[46] Tiwari GN, Dubey S. Fundamentals of photovoltaic modules and their applications. Cambridge, U.K.: RSC Pub./Royal Society of Chemistry. 
[47] Pishgar-Komleh SH, Keyhani A, Sefeedpari P. Wind speed and power density analysis based on Weibull and Rayleigh distributions (a case study: Firouzkooh county of Iran). Renewable and Sustainable Energy Reviews. 2015;42:313-22.

[48] Kaltschmitt M, Streicher W, Wiese A. Renewable energy,Technology,Economics ans Environment. Berlin Heidelberg: Springer-Verlag; 2007.

[49] Ardakani FJ, Riahy G, Abedi M. Design of an optimum hybrid renewable energy system considering reliability indices. ICEE 2010,2010.

[50] Silva SB, de Oliveira MAG, Severino MM. Economic evaluation and optimization of a photovoltaic-fuel cell-batteries hybrid system for use in the Brazilian Amazon. Energy Policy. 2010;38:6713-23. 


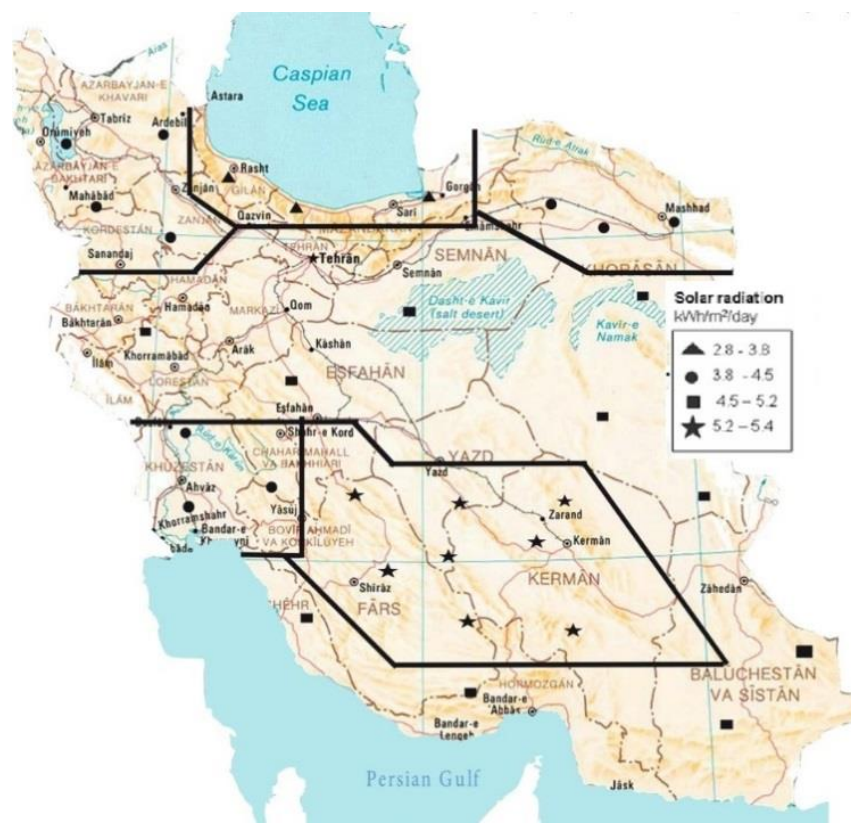

Fig 8: The solar radiation potential map of Iran

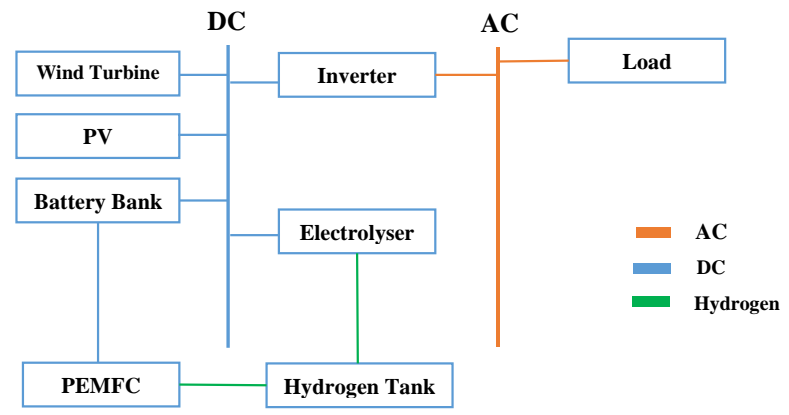

Fig 9: General schematic of the designed system 


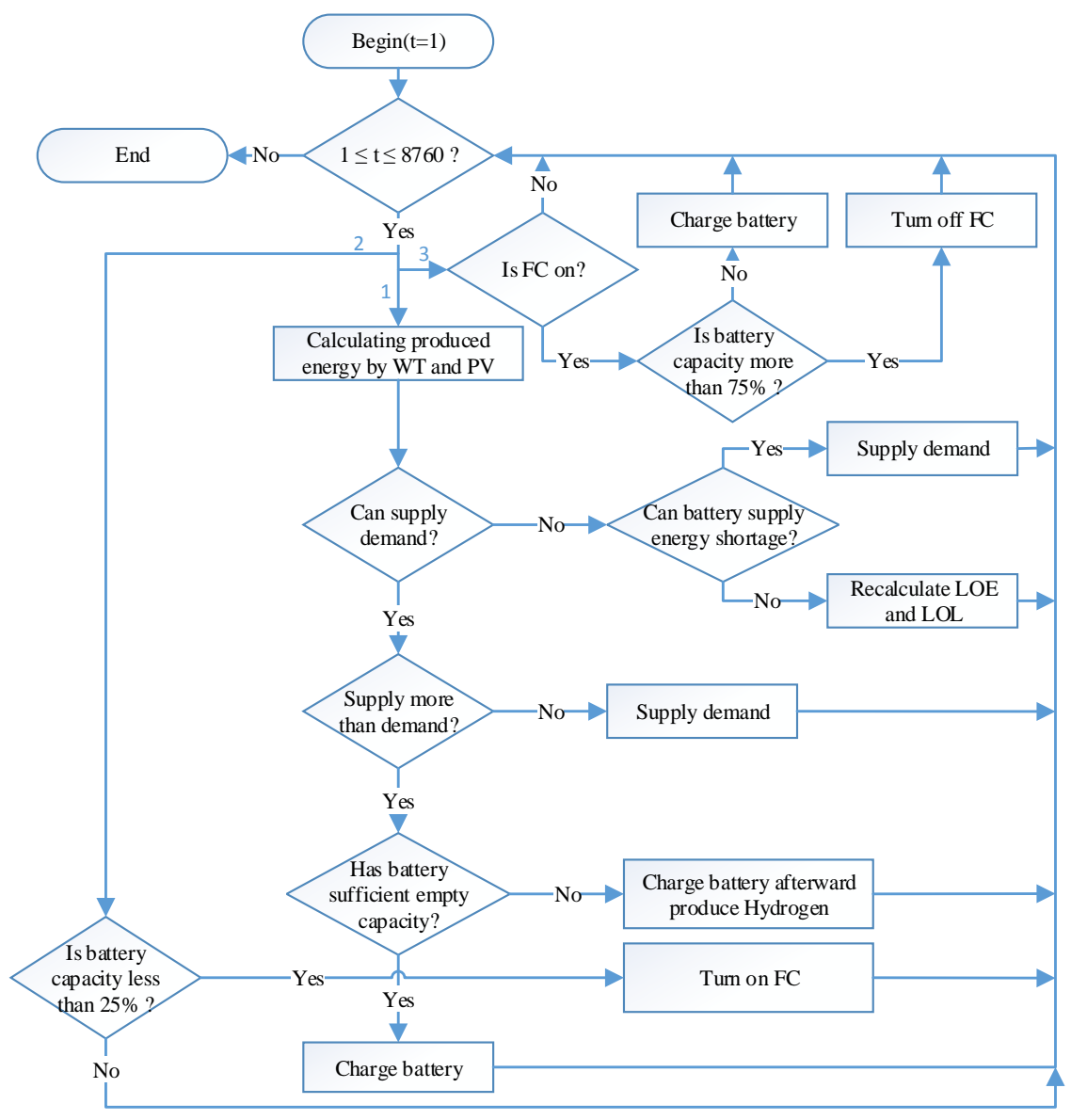

Fig 10: Optimization flowchart

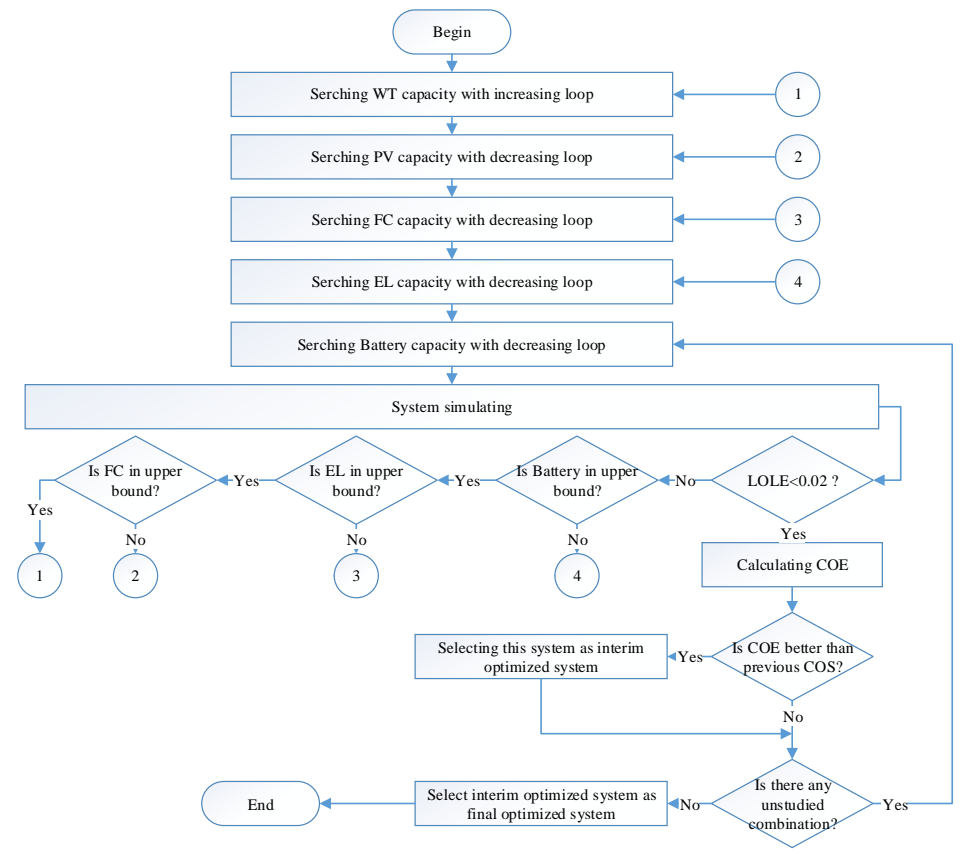

Fig 11: Simulation flowchart 

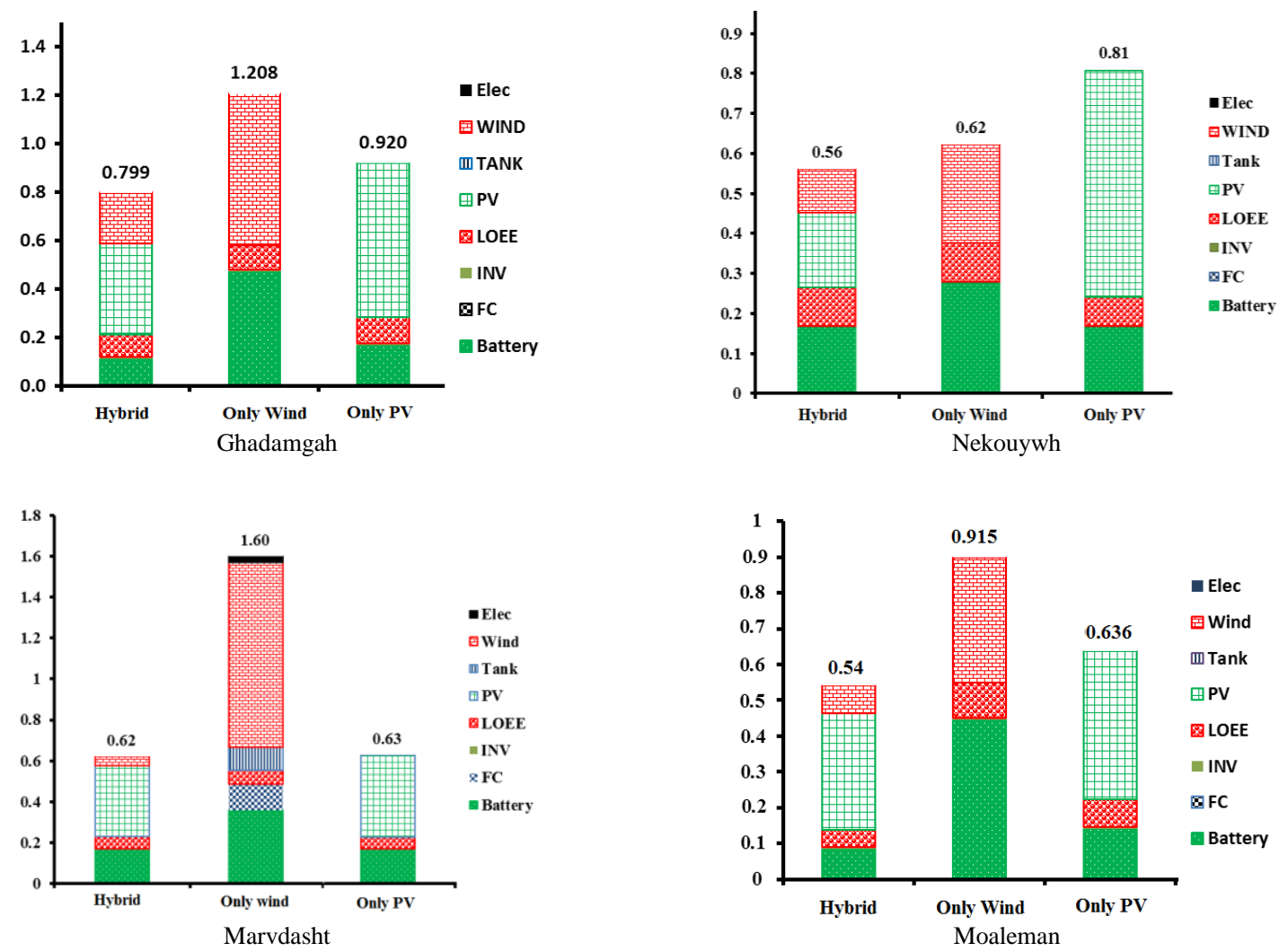

Fig 12: The results of optimization $(\$ / K W h)$

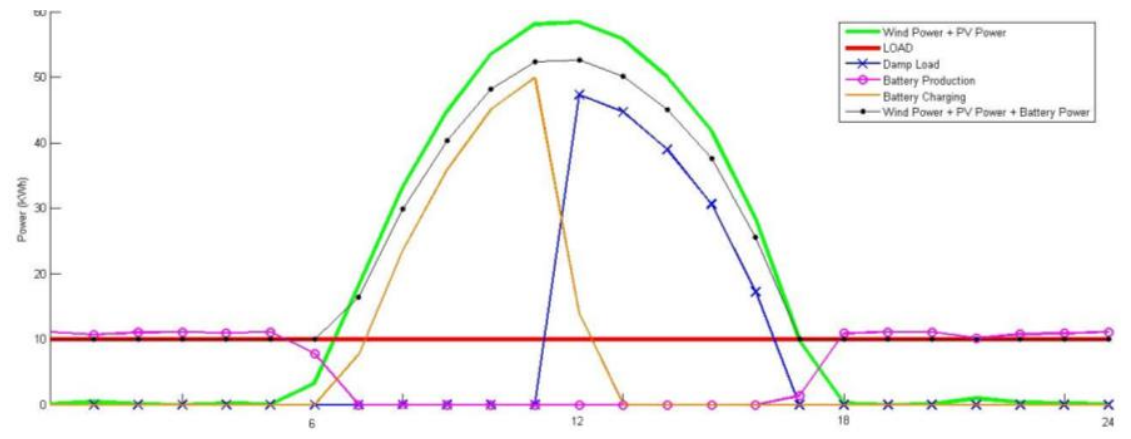

Jan. first 

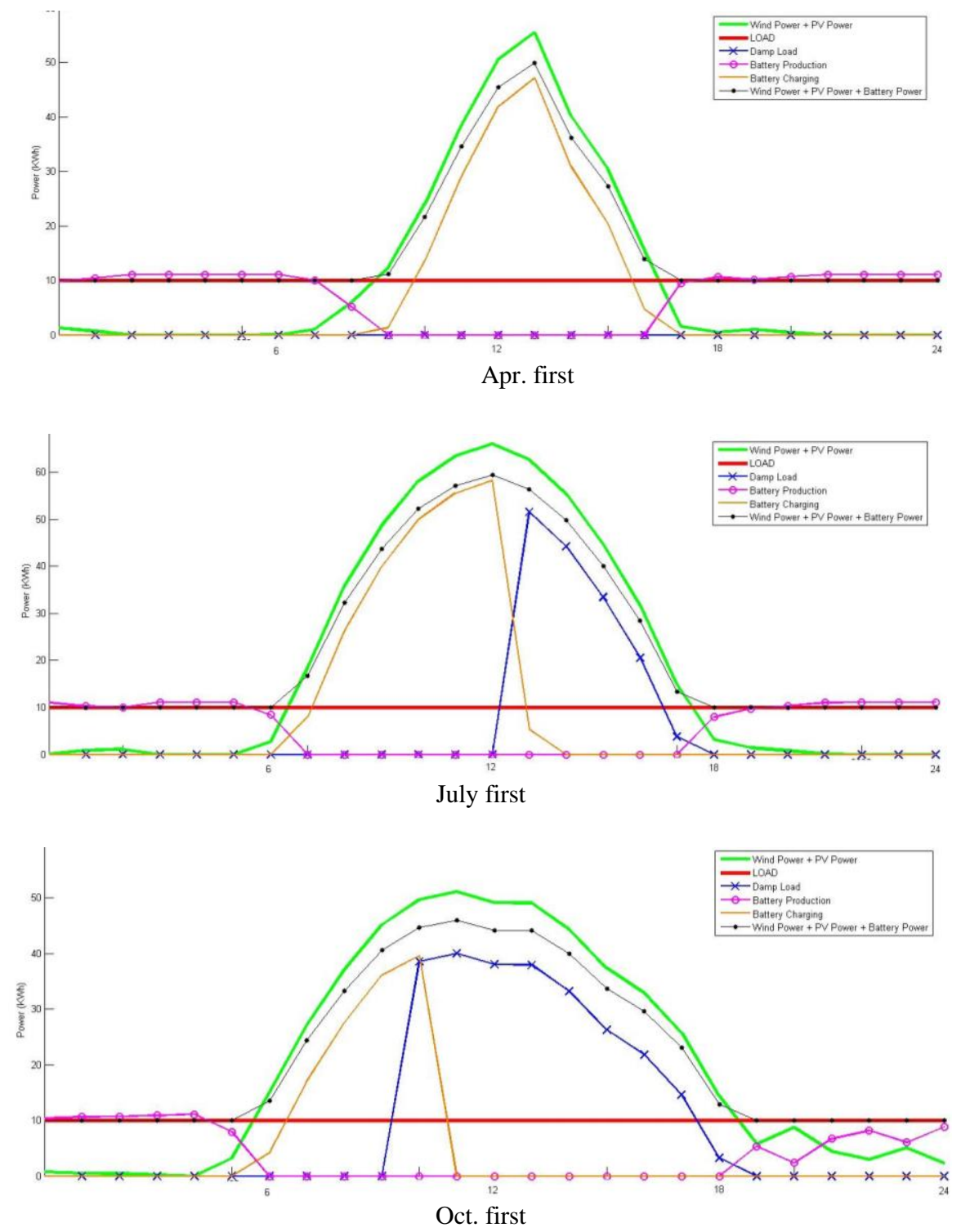

Fig 13 : The simulation results of hybrid system for four days

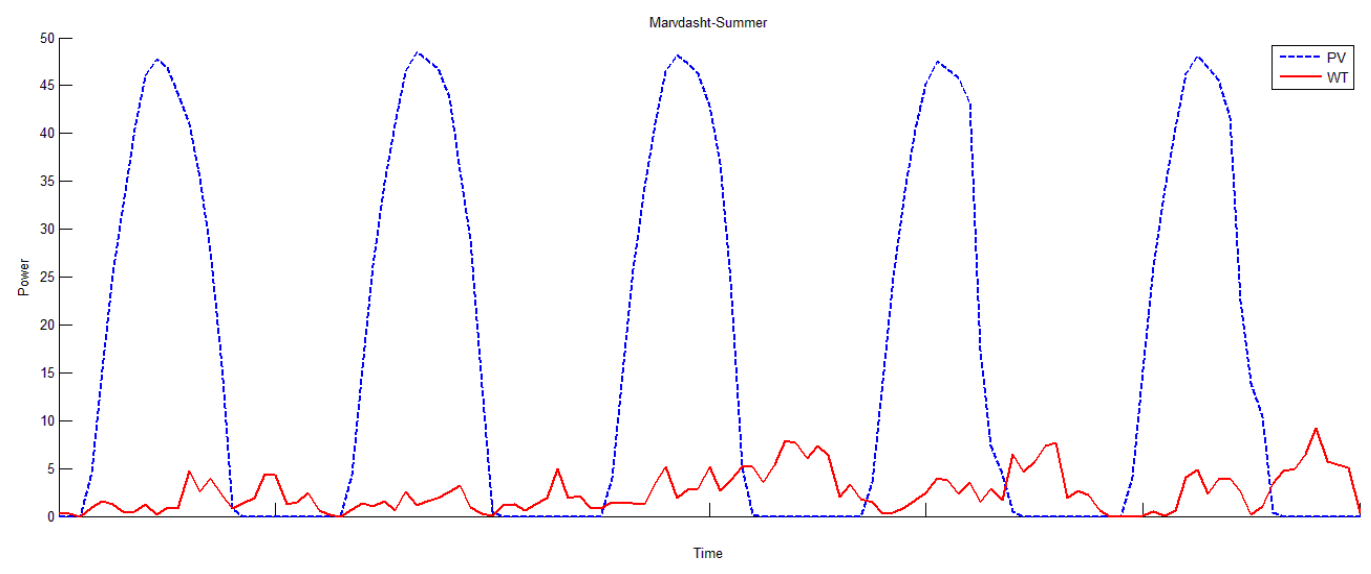

Fig 14: The simulation of WT and PV in Marvdasht 
Table 1

Cons and pros of battery and FC

\begin{tabular}{llll}
\hline & Energy density & Dynamics & Cost \\
\hline Batteries & low & fast & medium \\
FCs & high & slow & high \\
\hline
\end{tabular}

Table 2

Literature review

\begin{tabular}{|c|c|c|c|c|c|c|c|c|c|}
\hline Author's & Year & WT & PV & $\mathrm{FC}$ & Bat & Diesel & Other & Method & Tools \\
\hline Khan et al. [36] & 2009 & 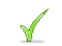 & - & M & - & - & - & Simulation & Simulink \\
\hline Leva et al. [33] & 2009 & & 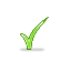 & $\mathscr{M}$ & $\mathscr{l}$ & $\mathscr{M}$ & - & $?$ & THERMIE $^{1}$ \\
\hline Karakoulidis et al. [34] & 2011 & - & $v$ & $\mathscr{L}$ & $\mathscr{L}$ & $\mathscr{l}$ & - & $?$ & HOMER \\
\hline Abedi et al. [9] & 2011 & & 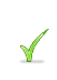 & $\mathscr{L}$ & - & - & - & $\begin{array}{l}\text { Mixed Integer Nonlinear } \\
\text { Optimization Problem }\end{array}$ & $?$ \\
\hline Jallouli et al. [37] & 2012 & - & r & $\mathbb{1}$ & $\mathscr{L}$ & - & - & $?$ & Simulink \\
\hline Abdolrahimi et al. [38] & 2012 & & 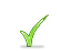 & - & $\mathscr{L}$ & $\mathscr{l}$ & - & $?$ & HOMER \\
\hline Asrari et al. [11] & 2012 & 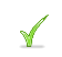 & $\mathscr{d}$ & - & $\mathscr{L}$ & $\mathscr{L}$ & - & $?$ & HOMER \\
\hline Fallahi et al. [13] & 2012 & 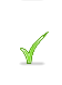 & $x$ & - & & - & $\begin{array}{l}\text { Tidal power } \\
\text { plant }\end{array}$ & $\begin{array}{l}\text { Optimization - Exact } \\
\text { methods }\end{array}$ & LINGO \\
\hline Amer et al. [39] & 2013 & & & - & $\mathscr{1}$ & $\mathscr{L}$ & - & $\begin{array}{l}\text { Particle Swarm Optimization } \\
\text { Technique }\end{array}$ & $?$ \\
\hline Iverson et al. [40] & 2013 & d & $\mathscr{d}$ & $\mathscr{L}$ & - & - & - & $\begin{array}{l}\text { Optimization routine } \\
\text { employing a search algorithm }\end{array}$ & $?$ \\
\hline Ghasemi et al. [12] & 2013 & - & $\mathscr{L}$ & - & $\mathscr{L}$ & $\mathscr{L}$ & - & - & HOMER \\
\hline Feroldi et al. [41] & 2014 & $\checkmark$ & $y$ & $\mathscr{1}$ & $x$ & - & $\begin{array}{l}\text { Bioethanol } \\
\text { Reformer }\end{array}$ & Genetic algorithm & $?$ \\
\hline Tao Ma et al. [42] & 2014 & $\mathscr{L}$ & & - & $\mathscr{l}$ & - & - & $?$ & HOMER \\
\hline Rohani et al. [43] & 2014 & $d$ & $\mathbb{d}$ & - & M & $\mathscr{l}$ & - & $?$ & HOMER \\
\hline Nogueira et al. [44] & 2014 & $\mathscr{d}$ & & - & $\mathscr{L}$ & - & - & $\begin{array}{l}\text { Iterative procedure in } \\
\text { Linear Programming }\end{array}$ & MATLAB \\
\hline This paper & - & $\mathscr{L}$ & $\mathscr{l}$ & $\mathscr{l}$ & $\mathscr{l}$ & - & - & $\begin{array}{l}\text { Iterative simulation- } \\
\text { optimization procedure }\end{array}$ & MATLAB \\
\hline
\end{tabular}

Table 3

Climate data of four studied regions

\begin{tabular}{lccc}
\hline Region & Wind speed Average (Height 40 meters $)$ & Solar radiation Average $\left(\mathrm{kWh} /\left(\mathrm{m}^{2} \times\right.\right.$ Day $\left.)\right)$ & Temperature $\left({ }^{\circ} \mathrm{C}\right)$ \\
\hline Nikouyeh & 7.2 & 5 & 8.6 \\
Ghadamgah & 5.3 & 5.1 & 15.5 \\
Moaleman & 6.1 & 5.77 & 20.7 \\
Marvdasht & 3.4 & 6 & 18.6 \\
\hline
\end{tabular}

Table 4

Used data for simulation of Crystalline PVs

Rated module efficiency $\left(\eta_{r}\right) \quad 15 \%$

Temperature coefficient of efficiency $(\beta) \quad 0.0045$

Normal operation cell temperature (NOCT) $\quad 55^{\circ} \mathrm{C}$

Temperature of Rated efficiency $\left(T_{r}\right) \quad 25{ }^{\circ} \mathrm{C}$

\footnotetext{
${ }^{1}$ Programme (EEC) for the promotion of energy technology in Europe
} 


\begin{tabular}{ll}
\hline Solar radiation in NOCT $\left(I_{N O C T}\right)$ & $800 \mathrm{~W} / \mathrm{m} 2$ \\
Life & 25 years \\
Capital cost & $\$ 3000$ per kW \\
O\&M cost & $2 \%$ of the capital cost \\
\hline
\end{tabular}

Table 5

WT data

Capital Cost

O\&M Cost

Life \$2000 per kW

Hellman coefficient $(\alpha) \quad 0.25$

$\rho$

$\underline{C_{p, t h}}$

1.08

$42 \%$

Table 6

Battery data

\begin{tabular}{ll}
\hline & $250 \mathrm{Ah}, 12 \mathrm{~V}(3 \mathrm{kWh})$ \\
\hline Capital Cost & $\$ 400(\$ 130$ per $\mathrm{kWh})$ \\
Life & 5 years \\
Scarp salvage value & $10 \%$ of capital cost \\
BRE & $80 \%$ \\
BDOD & $75 \%$ \\
\hline
\end{tabular}

Table 7

The specifications of FC and its accessories

\begin{tabular}{ll}
\hline & \multicolumn{1}{c}{ FC } \\
\hline Initial cost & \$4000 per kW \\
Replacement cost & $80 \%$ of initial cost \\
Life & $\begin{array}{l}\text { Minimum(2000 hours, 500 turn on and off } \\
\text { cycle) }\end{array}$ \\
Replacement life & 5 percent of initial cost \\
O\&M cost & 10 percent of replacement cost \\
Scrap value & $50 \%$ \\
FC Efficiency & \multicolumn{1}{c}{ HT } \\
\hline & $500 \$ / \mathrm{Kg}$ \\
\hline HT cost & 15 years \\
HT life & \multicolumn{1}{c}{ EL } \\
\hline & $2700 \$ / \mathrm{Kw}$ \\
\hline EL cost & 20 years \\
EL life & 74 percent \\
EL efficiency & 4 percent of the capital cost \\
EL O\&M cost & \multicolumn{2}{l}{} \\
\hline
\end{tabular}

Table 8

Used data in objective function

The annual real interest rate $5 \%$ per year

Lower heating value for hydrogen $\quad 120 \mathrm{MJ} / \mathrm{Hg}$

Cost of energy shortage $\$ 5.6$ per kWh

Table 9

Optimization results

\begin{tabular}{|c|c|c|c|c|c|c|c|c|}
\hline Regions & $\begin{array}{l}\text { WT capacity } \\
(\mathrm{KW})\end{array}$ & $\begin{array}{c}\text { PV capacity } \\
(\mathrm{KW})\end{array}$ & $\begin{array}{c}\text { Battery Capacity } \\
\text { (KWh) }\end{array}$ & $\begin{array}{c}\text { FC Capacity } \\
(\mathrm{KW})\end{array}$ & EL capacity $(\mathrm{KW})$ & $\begin{array}{c}\mathrm{HT} \\
\text { capacity }(\mathrm{Kg})\end{array}$ & $\operatorname{LOEE}(\%)$ & $\begin{array}{c}C O E \\
(\$ / \mathrm{KWh})\end{array}$ \\
\hline \multicolumn{9}{|c|}{ Hybrid system } \\
\hline Nikouyeh & 30 & 35 & 360 & 0 & 0 & 0 & 1.997 & 0.56 \\
\hline Ghadamgah & 60 & 70 & 240 & 0 & 0 & 0 & 1.66 & 0.799 \\
\hline
\end{tabular}




\begin{tabular}{|c|c|c|c|c|c|c|c|c|}
\hline Moaleman & 22 & 61 & 180 & 0 & 0 & 0 & 1.16 & 0.54 \\
\hline Marvdasht & 12 & 65 & 360 & 0 & 0 & 0 & 1.09 & 0.62 \\
\hline \multicolumn{9}{|c|}{ Wind system } \\
\hline Nikouyeh & 70 & & 600 & 0 & 0 & 0 & 1.87 & 0.62 \\
\hline Ghadamgah & 180 & & 1020 & - & - & - & 1.78 & 1.21 \\
\hline Moaleman & 100 & & 1020 & 0 & 0 & 0 & 1.8 & 0.92 \\
\hline Marvdasht & 260 & & 780 & 3 & 12 & 306 & 1.16 & 1.6 \\
\hline \multicolumn{9}{|c|}{ PV } \\
\hline Nikouyeh & & 106 & 360 & 0 & 0 & 0 & 1.41 & 0.81 \\
\hline Ghadamgah & & 119 & 360 & 0 & 0 & 0 & 1.99 & 0.918 \\
\hline Moaleman & & 77 & 300 & 0 & 0 & 0 & 1.5 & 0.64 \\
\hline Marvdasht & & 75 & 360 & 0 & 0 & 0 & 1.16 & 0.63 \\
\hline
\end{tabular}

